\title{
AC 2010-1227: WHAT THEY SAY MATTERS: PARENTAL IMPACT ON PRE-COLLEGE ACADEMIC IDENTITY OF SUCCESSFUL AFRICAN AMERICAN ENGINEERING STUDENTS
}

\section{Quintin Hughes, University of Oklahoma}

Quintin Hughes is an Industrial Engineering doctoral student at the University Of Oklahoma with a research emphasis in engineering education. More specifically, he's interested in identifying common success factors amongst successful African American engineering students. Quintin seeks to make his mark on the world via service in education and believes that exposure and enrichment of under-represented youth are key ingredients to their advancement in the sciences.

\section{Randa Shehab, University of Oklahoma}




\section{What they say matters: Parental Impact on Pre-college Academic Identity of Successful African American Engineering Students}

\section{Abstract}

Prevailing disidentification literature confirms that African American students academically disidentify via a weakened connection between academic achievement and global self-esteem. ${ }^{1-5}$ Research on achievement provides insight as to the people and factors that may influence the academic achievement of African American adolescent youth. Findings implicate the role of parents as well as parent-related variables such as socio-economic status, education level, support, involvement, and restrictive control. Contemporary literature examining academic disidentification and achievement across academic disciplines has failed to address engineering disciplines or understand the experiences of successful students and how the people in their lives may have impacted their academic identities.

In this study, a mixed methodology was used to study 19 African American participants who had reached either of two defined levels of success: (1) having successfully begun to pursue a degree in an engineering discipline, or (2) having successfully graduated with a bachelor's of science degree in an engineering discipline at a major south-central predominantly white university. Each participant was surveyed to evaluate their academic identity and interviewed to understand their pre-college lived experiences in regards to the prominent people in their lives and the messages related to academics (academic messages) they received from these people. The qualitative analysis of this rich data set allowed interpretation of the participants' experiences to determine how they were influenced to avoid disidentification and to become successful African American engineering students.

Preliminary surveys resulted in strong self-reported academic achievement and selfesteem via the Rosenberg self-esteem scale indicating that our participants were academically identified. ${ }^{6}$ Findings from the qualitative analysis suggested that parents and teachers were the most commonly cited prominent people and academic messengers in the lives of successful African American engineering students. Both were found to have sent a substantial number of academic messages and were identified by participants as having the largest impact on their academic and Science, Technology, Engineering, and Mathematics (STEM) identities. Parents were generally more important to participants than were teachers. Participants mentioned messages pertaining to academics from parents more than twice as often as they did teachers. Parents were also referenced by more than half of the participants for having the biggest impact on their own academic identities.

Though parents were categorized as a single unit, mothers and fathers often had separate roles in regards to the participants' academic identities. In two-parent households, students were closer to their mothers than their fathers. Mothers most often handled the proactive day-to-day academic business (monitoring, encouragement, support); fathers more often provided supplemental support. In single parent households, mothers most often played a dual role of both primary provider and academic manager. The consistent prominence of mothers in both single and two-parent households demonstrated their impact as the most influential people on the academic identities of our participants. These results will inform recommendations for engineering recruiters and academic support personnel. 
"All children have an innate interest in science and the world around them. But for many children, that interest hits roadblocks along an academic system that is still not blind to gender or color. These roadblocks have nothing to do with intellect, innate ability, or talent... As students, they cannot change the fact that they do not have access.... But adults can. And we must."

-Mae C. Jemison, eSchool News

\section{Introduction}

According to United States Census Bureau estimates, in 2006 nearly 28\% of our nation's population consisted of Black and Hispanic Americans while White and Asian Americans represented nearly $67 \%$. However, of over 22.6 million scientists and engineers in the U.S., Black and Hispanic Americans represented 2.5 million (under 10.8 \%) while White and Asian Americans represented 19.6 million (nearly $87 \%$ ). These percentages illustrate the vast disparity between the representation of White and Asian Americans and underrepresented minority groups in the science and engineering workforce. The engineering workforce has an even more disparate representation of underrepresented minorities with African American and Hispanic Americans comprising only $4.7 \%$ of engineers, while White and Asian Americans represent 95\%. National Science Board studies encourage the government's leading science and engineering (S\&E) organizations to consider under-represented groups as un-tapped resources with enormous potential for building the S\&E workforce. ${ }^{7-10}$ Nearly $80 \%$ of surveyed underrepresented chemists and chemical engineers believed that women and underrepresented minorities do not participate in the STEM fields because they are not encouraged to do so at a young age. The problem is exacerbated in college with $60 \%$ responding that college is a place of active discouragement. The study found pervasive stereotypes "that STEM isn't for girls or minorities" as one of the major contributors to underrepresentation in the sciences. ${ }^{11}$

Many researchers working toward the common goal of increasing recruitment, enrollment, and graduation of African Americans in engineering have attributed much of the disparity between African Americans and White and Asian Americans in engineering colleges and the engineering workforce to the "achievement gap" between Black students and their White and Asian counterparts during their K-12 education. The literature points to many reasons for this gap including poor schools, poor preparation, and lack of interest. ${ }^{12-14}$ One of the most intriguing and widely accepted explanations was introduced in Claude Steele's Race and the Schooling of Black Americans. Here Steele introduced disidentification theory which claims that African American students de-emphasize academics in order to maintain self-esteem in the face of poor academic performance. ${ }^{15}$ Numerous studies have supported, expounded upon, and attempted to explain reasons behind the disidentification theory among black students. ${ }^{1-5}$ Few if any studies to this point have (a) shown a specific interest in engineering students, (b) sought to flip the paradigm by studying high achieving black students who display an identification (rather than disidentification) with academics, and (c) used a qualitative approach to explore and understand this phenomenon or lack thereof.

The purpose of this report is to use the pre-college lived experiences of successful (academically identified) African American engineering students to understand how the academic messages from prominent people in their lives shaped participant academic identities and interest in engineering. To develop this understanding, the study answers the following research questions about the pre-college lives of successful (academically identified) African 
American engineering students: (1) Which people sent the most academic messages? (2) Which messages most impacted academic and science, technology, engineering, and mathematics (STEM) identity? (3) And what people most impacted academic and STEM identity?

This study relies largely on qualitative data due to its need to identify and understand the academic messages received by successful African American engineering students. According to Creswell, "Interactions among people... are difficult to capture with existing measures, and these measures may not be sensitive to issues such as gender differences, race, economic status, and individual differences. To level all individuals to a statistical mean overlooks the uniqueness of individuals". ${ }^{16}$ In this study successful African American engineering students are considered an uncommon phenomenon (due to national trends in African American recruitment, retention, and graduation in engineering). For this reason, a phenomenological qualitative research approach was taken. This methodological approach focuses on understanding the perceptions of those who have experienced or are part of the same phenomenon. ${ }^{17}$ This methodology permits a deeper understanding of individuals who experienced engineering success as African Americans and of their relationships with the people who helped to develop their academic identities.

Literature Review

\section{Disidentification Literature}

Steele hypothesized that negative social images of academic and intellectual inferiority pressed upon blacks in America have led to a phenomenon called "stereotype threat" that affects the intellectually capable African American. ${ }^{15}$ Steele believes that African Americans are threatened by the fear of confirming negative societal stereotypes. This theory postulates that over time, being placed in stereotype threatening environments may cause high achieving black students to de-value the importance of academic achievement as critical to their overall selfconcept in order to maintain self-esteem, resulting in intellectual underperformance. This condition is what has become known as academic disidentification. Steele acknowledged that those who attend predominantly white colleges may be more susceptible to stereotype threat as a result of their under-representation. Several studies report results that support the existence of academic disidentification and stereotype threat among African American students. ${ }^{1-5,15}$

\section{Influences}

Parents can be important influences in the pre-college lives and academic engagement of students. ${ }^{18-21}$ Sharp et al. utilized NELS longitudinal data and suggested that African American parents positively impact their student's desire to attend college, but were not guiding them through important aspects of college preparation. ${ }^{21}$ Gonzales et al. studied peer and neighborhood influence on the academic achievement of African American junior high school students and found that parenting variables such as maternal support and restrictive control (although moderated by neighborhood risk) were the strongest influences on academic achievement. ${ }^{18}$ Israel et al. examined the influences of both family and community social capital on academic achievement of high school students and found that family structure, family income, parental education, and parental involvement significantly influenced academic achievement of students of all races (including African Americans). ${ }^{19}$ Bankston \& Caldas examined the effects of school peers on the academic achievement of African American students 
suggesting that attending minority-concentrated high schools with a large prevalence of peers from single-parent female households negatively impacts academic achievement. ${ }^{22}$

\section{African Americans in Engineering}

Little to no literature specifically addresses how African American students identify with STEM. What has been addressed in abundance though is the educational achievement gap between African American students and majority students. ${ }^{12-14,22}$ The large achievement gap may partially explain why African American students struggle to enroll, be retained, and graduate in STEM-related fields at proportions equal to their population percentage, while majority students not only meet their own percentages, but exceed them. Numerous studies and reports have highlighted the need for more African American STEM professionals and have called for increased enrollment, retention, and graduation of African Americans. ${ }^{10,23-33}$ Though several studies have shown that special programs can aid in increasing retention and graduation rates in STEM related fields, ${ }^{34}$ few have addressed how to aid African American students in developing STEM identity prior to attending STEM institutions.

Methodology

\section{Context for the Study}

This study took place at a major predominantly white research university located in the south central region of the U.S. At the time, the total undergraduate enrollment of this institution was nearly 19,000 (74\% white, $5.7 \%$ black) with an engineering student population of around 2,000 (69\% white, $6.2 \%$ black). To identify potential participants, the College of Engineering $(\mathrm{CoE})$ and the Multicultural Engineering Program (MEP) within the CoE provided contact information for all African American engineering Fall 2007 entering freshman and recent engineering alumni (between 2000 and 2007). All of the participants volunteered without compensation.

\section{Description of Sample}

It is important to understand that producing generalizations is not the purpose of qualitative research. "Rather, participants are selected purposefully. "The logic and power of purposeful sampling... leads to selecting information-rich cases for study in depth. Informationrich cases are those from which one can learn a great deal about issues of central importance to the purpose of the research... (Patton 2002, 46)." 35 To gain a deeper understanding of the experiences of successful black undergraduate engineering students during their pre-college lives, students were targeted at two stages of success: high school success (having successfully completed high school and been accepted into the College of Engineering) and collegiate success (having successfully earned a bachelor's degree from the College of Engineering). Therefore, entering freshmen and $\mathrm{CoE}$ alumni were targeted as potential participants of the study. Entering freshmen were expected to give a fresher description of their high school experiences, while alumni were expected to provide more insight regarding their collegiate success.

Again, this study is phenomenological and within this methodological framework only 310 participants are recommended. ${ }^{16}$. This study recruited nine entering freshmen and eleven alumni (20 total participants). However, interview data from one male alumnus was lost, leaving an overall sample of nineteen participants (58\% female, $42 \%$ male). Table 1 provides gender and classification breakdowns of the sample. 
Table 1. Participant Demographics.

\begin{tabular}{|l|c|c|c|}
\cline { 2 - 3 } \multicolumn{1}{c|}{} & \multicolumn{2}{c|}{ Gender } & \multicolumn{1}{c}{} \\
\hline Classification & Female & Male & Total \\
\hline Freshman & 5 & 4 & $\mathbf{9}$ \\
\hline Alumni & 6 & 4 & $\mathbf{1 0}$ \\
\hline Total & $\mathbf{1 1}$ & $\mathbf{8}$ & $\mathbf{1 9}$ \\
\hline
\end{tabular}

All participants self-reported as African American or Black in their original college application as well as in the study's preliminary survey. All entering freshmen participants were 18 years of age, and all alumni graduated from the College of Engineering between the years of 2000 and 2005 (an average of 4.4 years since self-reported graduation). Note that though African American females were over-represented in the sample (nearly 58\%), they represented less than $38 \%$ of the African American CoE undergraduate population. Their overrepresentation in the sample was due to higher levels of response during recruitment.

Though perhaps not proportional to socio-economic demographic representation among African-Americans in the U.S., even this small sample has representatives of major demographic groupings. A majority of participants lived in middle-income households, with two parents present (at least one with a bachelor's degree). However, one-third were raised by their mothers alone and/or in low-income households. Two students grew up in affluent homes. Tables 2, 3, and 4 show the family structures, household income level, and household education level of all participants. Of the 19 participants, two had parents who hadn't attended college. Most of the participants came to college from families with significant academic capital, notably a factor in the student's own academic success. Twelve participants came from families in which the parents had earned bachelor's or graduate degrees in college. Five other participants had parents with some collegiate experience, with two of those completing associate's degrees.

Tables 2, 3, and 4. Household Structure, Income, and Education.

\begin{tabular}{|l|c|}
\hline Family Structure & Participants \\
\hline Both Biological Parents & 10 \\
\hline Parent \& Step-parent & 2 \\
\hline Single Mother & 7 \\
\hline Total & $\mathbf{1 9}$ \\
\hline
\end{tabular}

\begin{tabular}{|c|c|}
\hline Household Income & Participants \\
\hline$\$ 100,000-\$ 199,999$ & 2 \\
\hline$\$ 49,000$ - \$99,999 & 9 \\
\hline$\$ 25,000$ - \$49,999 & 6 \\
\hline$\$ 0$ - \$24,999 & 2 \\
\hline Total & 19 \\
\hline
\end{tabular}

\begin{tabular}{|l|c|}
\hline Household Education & Participants \\
\hline Beyond college graduate & 6 \\
\hline College graduate (Bachelors) & 6 \\
\hline College graduate (Associates) & 2 \\
\hline Some college & 3 \\
\hline High school graduate & 2 \\
\hline Total & 19 \\
\hline
\end{tabular}

\section{Methodological Design}

Though the study's design is heavily qualitative, a mixed methods approach was used. Mixed methods procedures are used for collecting, analyzing and integrating both quantitative and qualitative data at some stage of the research process with a single study. ${ }^{16}$ The purpose behind using a mixed methodology was (1) to use quantifiable survey data to measure the participants' level of overall academic performance, math and science performance, academic engagement, and self-esteem to verify that they identified academically and (2) to use qualitative techniques to gain richer insight as to how their identities developed. A preliminary survey was used to provide background information, inform the interview protocol, and verify the academic 
identification of participants. Background variables included college classification, college major, gender, family structure, family income, and family education level. In addition, the survey included the well-known Rosenberg self-esteem questionnaire to measure self-assessed self-esteem. ${ }^{6}$ Participant academic identification was established by comparing Rosenberg scores with self-reported high school academic performance.

Semi-structured interviews were conducted to gain an understanding of the lived experiences of the participants that would enable the study to answer the research questions. ${ }^{16}$ Two forms of qualitative analysis were used for the interview analysis, allowing for investigation of anticipated factors developed from previous literature and researcher experience. Also, the methodology was structured to more easily identify themes related to the research questions.

Content analysis is generally used for qualitative data when categories have been identified from pre-existing theory. This form of analysis involves dispersing data into categories and frequency counting, which can be used in quantitative analyses. ${ }^{36}$ Thematic analysis is used to identify themes in qualitative data via a process of "coding." Coding attempts to describe what the data is about. ${ }^{36}$ Over 650 pages of transcript text were analyzed using these methods throughout this study. Due to the overwhelming amount of data, traditional methods of qualitative analysis were impractical, therefore NVivo 7 (QSR International) computer assisted qualitative data analysis software package was used to facilitate analysis.

Results

\section{Quantitative Measures of Academic Identity}

Academic identity was established by combining measures of academic performance and self-esteem. Performance was measured via self-reported high school grade point average (GPA) and letter grades earned in math and science courses. Math and science course grades were used to better understand the participant's pre-college performance in STEM courses. All participants earned high school GPA's of 3.0 or above out of a 4.0 scale ( 15 obtaining a 3.5 or above) and reported math and science grades between "A" and "C" (18 of 19 students reporting "B's" or greater, 13 reported "A's"). Figures 1 and 2 represent the samples of self-reported overall high school GPAs and math and science course grades. These grades indicate a high level of overall high school academic and STEM achievement among this sample.
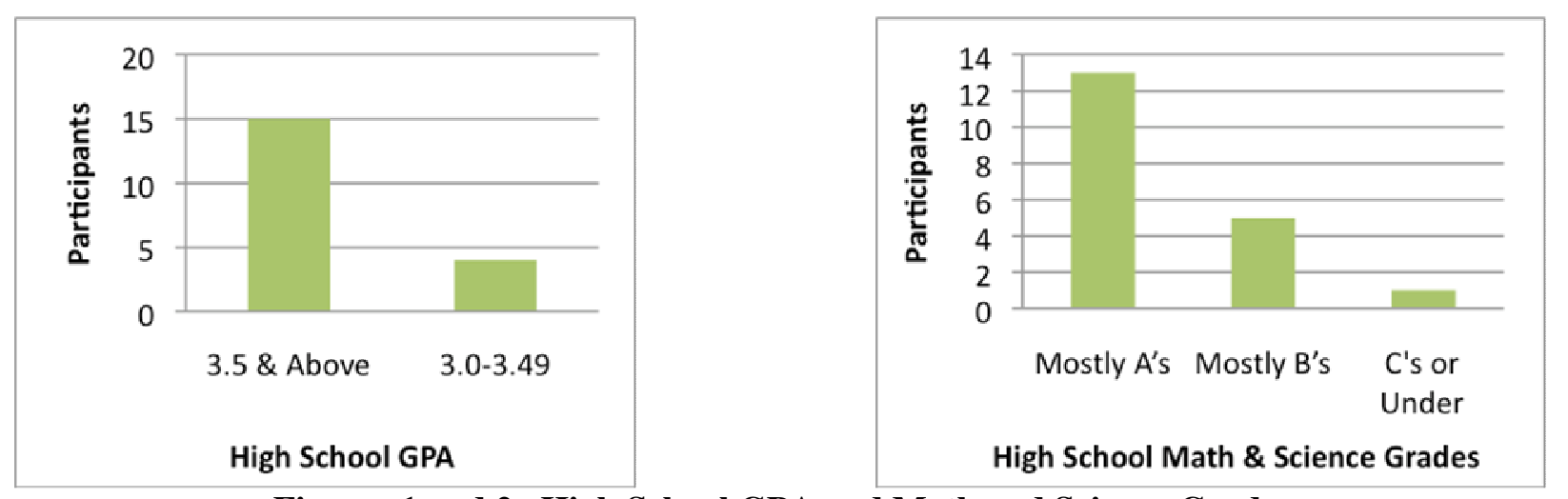

Figures 1 and 2. High School GPA and Math and Science Grades.

The Rosenberg Self-Esteem Scale was used to measure the overall self-esteem of each participant reflecting on their pre-college lives. ${ }^{6}$ On a scale of 0 to 30 , participants reported a 
mean self-esteem score of 25.6 (SD 4.18), compared to a normed average for the Rosenberg test of approximately $20 .{ }^{37}$ This score indicates that the participants came to college with high selfesteem.

In sum, prior to their collegiate experience, participants performed at a high level academically (overall and specifically in STEM) and held high self-esteem. Although the previously mentioned literature has reported using achievement and self-esteem measures to measure academic disidentification, ${ }^{1-3}$ the current study is unique in that it uses these measures to assess the participants' identification with academics (as opposed to disidentification). Therefore, the combination of these factors (high achievement and high self-esteem) indicates that as a group, these participants were overall academically and STEM identified.

\section{Qualitative Interview Analysis}

\section{Who is sending academic messages?}

Interview passages that were interpreted as critical to the participant's formation of opinions toward their own academic achievement were categorized as academic messages. They were also coded to any person (or persons) who sent them. Table 5 shows the overall number of text passages that were categorized as academic messages, disaggregated according to the person or messenger who sent the message.

Table 5. Academic Messages by Prominent People.

\begin{tabular}{|l|c}
\hline Prominent People & Academic Messages \\
\hline Parents & 550 \\
\hline Peers & 285 \\
\hline Teachers & 210 \\
\hline Siblings & 156 \\
\hline Other Prominent People & 133 \\
\hline Other Family & 108 \\
\hline Total & $\mathbf{1 4 4 2}$ \\
\hline
\end{tabular}

Overall, academic messages from parents occurred nearly twice as often as from any other person mentioned by participants. Parents accounted for 550 total messages or an average of 31 messages per participant, making them by far the most prolific group of messengers in the study. The high prevalence of academic messages from parents may be attributed to their overall educational background. As shown in Table 4, of 19 participants' households, 17 had parents with college experience, 14 with at least an associate's degree, 12 with bachelor's degrees, and 6 with degrees higher than bachelor's. The educational attainment of this group of parents may demonstrate that they possess an understanding of the value of education and see academic identity as directly relevant to their child's future. Also, in general parents usually have increased opportunities for one-on-one conversations with their children where their messages can be shared.

\section{Which messages had the most impact on academic/STEM identity?}

The messages identified as most impactful somewhat varied across participants, however the majority of the messages clustered into two themes: (1) messages that promoted the use of 
education as a tool to become professionally and/or financially successful, and (2) messages that alluded to unlimited potential and possibilities for their future.

Messages that promoted the use of education as a tool seemed to support participant's confidence in their own academic abilities, while messages that cited great potential appeared to highlight their opportunity to become high achieving individuals. Participants often viewed a degree in engineering as a great achievement and direct pathway to a prestigious and high paying profession. Their views of engineering and high confidence in their abilities may have encouraged their pursuit of a higher education in the challenging field of engineering.

\section{Which people had the greatest impact on academic/STEM identity?}

Participants overwhelmingly felt parents had the most impact on their academic and STEM development prior to college. Parents were identified by more than half of the participants and over twice as often as any other people. Table 6 presents the people that participants identified as having the most impact on the development of their academic/STEM identities. Note that the total number of responses is more than the number of participants; this is due to four participants identifying two most influential people.

Table 6. References to Impactful People.

\begin{tabular}{|l|c|}
\hline Most Impactful People & Number of References \\
\hline A parent or parents & 11 \\
\hline Teachers & 5 \\
\hline Brother & 2 \\
\hline Aunt or Uncle & 2 \\
\hline Computer science class & 1 \\
\hline No one & 1 \\
\hline Self & 1 \\
\hline Total & $\mathbf{2 3}$ \\
\hline
\end{tabular}

These results, coupled with those reported in Table 5 indicate the significance of parents as frequent and impactful messengers, and suggest that the frequency of messages may be an indicator of the strength of their impact on academic identity. However, peers were found to have sent many messages yet were not identified by participants as impactful people. The lack of perceived peer impact along with higher occurrences of parents and teachers as influential people may imply that participants were more receptive to academic messages from authority figures, and/or less susceptible to peer influence. This finding contradicts those of Gonzales et al., which found peer support to be a stronger predictor of academic achievement. ${ }^{18}$

In sum, parents were consistently found to be the most prominent academic messengers. They not only sent the most academic messages, but were also found to have had the greatest impact on how our participants came to identify academically. While this finding was not surprising, a closer look at interview content provided insight as to how they were able to be so influential. 


\section{The prominence of parents}

To further understand the role of parents, thematic analysis was used to identify common themes within the transcripts. The emergent themes provide insight into the meanings of the messages that helped shape the participants' academic identities. The most common themes to emerge relate to high academic expectations, academic support, and the close parent - child relationships.

\section{Academic Expectations}

Overall, parents held high academic expectations for the participants; however these expectations varied in intensity and form of expression. Some parents were specific in regards to the type of academic performance they expected, and participants seemed to know what the acceptable grade range was:

"the real emphasis was on making good grades, but you know I think that they wanted me to make A's and B's, really ... but it was like you know you have to make good grades. Because, you know with the emphasis of you know getting into a good college... I remember a time when I was in the 5th grade my dad told me that for every A that I got he would give me a \$100.00. So, on each report card obviously, my goal was to get all A's." (female alumnus)

"If I got a C, I got put on punishment. Well, wouldn't really punish me, they would sit me down and talk to me and try to make me feel bad, I guess. Then, I would start crying and then they'd start, "Well, its okay you know, just don't let it happen again.” I was like well, I'm trying my hardest. They'd be like, "Well, okay.” But, I couldn't really I wasn't supposed to get below a B. ”(female freshman)

Some participants didn't describe specific grade expectations imposed by their parents, but rather described parental reactions when the student received grades that were considered unacceptable:

"I think one time I got like a D and she [mother] almost took that house apart. It wasn't like that bad but at the same time she was really upset and she was like: <student's name>, you can do better. And I knew I could do better." (male freshman)

Not all parents were as concerned with grades as they were with the holistic development of their child as a student. Some participants described their parents' expectations by describing where their parents gathered information to evaluate their academic success:

"So, I wouldn't say they had unrealistic expectations, I think it was more that they kind of monitored to see what we were doing for ourselves, and kind of watched you know the reports from the teachers and how we interacted with our peers, whatever to see whether or not we were trying to get stuff done versus whether we were slacking off and just didn't get it because we didn't feel like it." (female alumnus) 
Ultimately, most participants were expected to perform well in high school so that they could obtain higher education and go on to reach their full potential:

"At a very young age, my parents had very high expectations for both me and my sister academically. One of the things they'd always said at a young age was that they knew that both me and my sister had the academic talent to perform well in school so the expectation is that we should always meet, you know, our full potential so they always expected us to do extremely well in school." (male alumnus)

"They've always wanted us to go to college. Like even before my dad I guess he decided to go back to school, he has always told me and my sister that we were going to go to college and we didn't have a choice. He was like, "Ya'll are going to go to college." (female freshman)

While not always clearly stated, it was evident that for many of the participants in this sample, their parents assumed that their child would attend college:

"it was always just an understood thing like the logical flow of life, you go to school, high school, I mean elementary school, high school, college and work. That was just the I mean the natural flow that I always understood growing up. And I guess, I even for a long time felt that that was the natural flow for everyone until interacting with more people my age who did not complete college who I found did not come from an environment where that was just the, you know, natural flow of life." (female alumnus)

\section{Academic Support}

Most parents did not hold these high academic expectations for their students without helping them along the way. Their consistent presence gave them opportunity to supplement those expectations with academic support:

"So, whether it was you know as I said earlier, staying after school, going early, meeting with classmates, meeting with tutors, whoever I needed to meet with to get it done they made sure that was possible as much as they could, as much as their schedule allowed." (female alumnus)

Though parents supported participants in numerous ways, most effort was used in academic monitoring. Many participants described ways in which their parents kept tabs on their school progress using terms like "watching" and "hands-on"

"So, my mom she was very active in watching... she was there you know helping me with my homework, so she knew that I was trying. She knew that I was trying to get feedback from different people at school and everything." (female alumnus) 
"she was very hands-on. As a matter offact, like anything I did in school, out of school, anywhere, she was always there. That would be... she would take like every day... get off work and come and see me. She took off like a week when I moved into college, like (?). But like at the same time like she's always been there, and so she feels like when I do good that means she did good because she rose... she took the time to raise me (yeah, rose me) (l). And so, uh, like she really pushed... she pushed pretty hard, like when it came to school." (male freshman)

Other participants described parental academic support that directly tracked their progress in school, both on a daily basis as well as through report cards:

"My mother would stay up late nights with me, helping me with my homework and making sure that I finished my homework no matter how hard it was, no matter how much I didn't want to do it, she was there." (female alumnus)

“... there were report cards. They knew. It was like: I haven't seen a report card in awhile. It was like 'parent sensors' or something; the reports cards came home today. ... we had the report cards... all the report cards pinned up to the bulletin board... so you could go ask my mom for my report card from my senior [year] in high school until I was like [in] first grade. She's got like all those... she just files them away." (male freshman)

\section{Parent-Child Relationships}

Though family structures varied, participants often talked about having close families. In two-parent homes, participants were often closer to their mothers.

"A very good relationship, close relationship with both my parents and they're still together, so they're still married. You know always supportive, just things they always encouraged me to do my best. (female alumnus)

"I was raised by both of them... we're real-real close. I mean I can talk to my mom about everything and she is understanding. They both disciplined me but they - I mean they're not harsh with it, but I'm a good child, so (laughter)! ... But, I mean we always do stuff together, we always go to church together on Sunday, and they're really supportive... when I was in high school they went to all my games and all my stuff at school. My mom was always taping me on videos and stuff, so we're a real close family." (female freshman)

"I had a really good relationship with both of my parents. They were both in all aspects of my life and participated in both participated in everything, pretty much that I did. But, my mother was my primary caregiver on a day-to-day basis." (female alumnus) 
"I'm a Mamma's boy. My mom took an active role in raising me. Not that my dad didn't, but he worked ridiculous hours as I was growing up. But, he always supported my education, obviously." (male alumnus)

In most single parent households, mothers were the dominant caregivers and usually closer.

“My mom was my... pretty much my best friend... she's awesome, you know...my dad was more so financially involved in my life... I was involved in sports my entire life and he didn't... he never came to any games or anything like that, and he was big in sports... it never made any sense to me. But my mom was there. My mom was my support system, you know. She made it so that I didn't rely on my dad for that kind of thing."(male freshman)

"My mother was always very, you know encouraging. So was my dad, but see I was around my mother a lot more and she just always knew that I could do, you know... and she is the reason why I've come this far. And it was my goal to... you know, to go to college without my mom having to pay a dime. You know, without having her to reach into her pocket, and that goal was accomplished because of some hard work." (male freshman)

While it is evident that parents have had the greatest impact on how participants came to identify academically, it should also be evident that often times mothers set the academic expectations, provided more of the academic support, and held closer relationships. This dominance was often the case in two-parent households, and mostly the case in single parent homes. Mothers were also found to have sent more academic messages than fathers. Table 7 shows the number of academic messages coded to mothers and fathers. Note that the sum of academic messages from "mothers" and "fathers" does not equate to the total number of messages from the "parents" category in Table 5. This is because 144 academic messages were coded to "parents" as a single unit rather than the individual parent.

Table 7. Parent Academic Messages.

\begin{tabular}{|l|c|}
\hline Parent & Academic Messages \\
\hline Mother & 233 \\
\hline Father & 173 \\
\hline
\end{tabular}

The results from Table 7 are not surprising, as several participants had only one parent to speak of (the majority of whom were mothers). Therefore, while compared to other influences, parents seem to have reached participants most, overall, mothers appear to have had the greatest impact on their students' academic identification.

Conclusions

In an effort to better understand the success of African American engineering students, this phenomenological study explored the pre-college lived experiences of successful African American engineering students. The goal was to understand how people in their lives may have 
impacted their identity with academics through the use of academic messages. To do this three research questions were asked: (1) Which people sent the most academic messages? (2) Which messages most impacted academic and science, technology, engineering, and mathematics (STEM) identity? (3) And what people most impacted academic and STEM identity?

Prevailing disidentification literature supported the existence of disidentification of African American students via a weakened connection between academic achievement and global self-esteem. ${ }^{1-3,5,38}$ Research studying achievement provided insight as to the people and the factors that influence the academic achievement of African American students. Findings strongly implicate the role of parents as well as parent-related variables such as socio-economic status, education level, support, involvement, and restrictive control.

A mixed methodology was used to study 19 African American participants who were either incoming engineering freshmen or engineering alumni of a major south-central university. Each participant was surveyed to evaluate their academic identity and interviewed to understand their pre-college lived experiences in regards to the prominent people in their lives, and the academic messages received from these people.

Overall, survey findings suggests that our participants earned high GPA's and high grades in their math and science courses during high school, and that our participants were academically identified. Findings from qualitative analysis suggest that parents are the most important academic messengers in the lives of successful African American engineering students. Parents sent more than twice the number of messages sent by teachers and were referenced by more than half of the participants as having the most impact on participant's academic and math and science identities. An explanation for the impact of parents may be their natural prominence in their adolescents' lives and that parents (as opposed to peers) have a longterm perspective of what it takes and means to be successful. Parents may also have more direct opportunities for one-on-one conversations and interactions with their children (as opposed to teachers) and consequently have greater impact on their children's development of academic identity. Parents described in this study utilized those opportunities to consistently stress the importance of education to participants along with their limitless potential in the future. Parents impacted participants' academic identities by establishing close relationships, setting high grade expectations, and providing academic support.

Within the parental unit, mothers more often were closer to participants and took on the lead role as academic managers who monitored grades and provided support when needed. This finding suggests that mothers had the overall biggest impact on the pre-college academic identification of these successful African American engineering students. An explanation for the impact of mothers may be their prominent role within the family structures represented in our sample. Several participants were raised in mother-only single-parent households, creating more opportunities for mothers to be the dominant academic influence. These findings agree with those of Gonzales who cites maternal support as a positive influence on academic achievement. ${ }^{18}$ In contradiction to the current study, other researchers suggest that mother-only single parent households negatively influence achievement. ${ }^{22}$ Perhaps the negative influence found by Bankston \& Caldas was moderated by the relatively high level of education held by the parents in this study. This finding suggests that parental education level may have impacted achievement, which is supported by the literature. ${ }^{19}$

In sum, our participants grew up with well-educated, supportive parents with whom they had strong relationships in their lives. These adults were found to have sent an abundance of academic messages by building strong relationships, setting high academic expectations, and 
supporting academically by monitoring their academic performances. Therefore, these findings suggest that parents/guardians should: (1) build close relationships with their children, (2) set high academic standards that make college an implicit and explicit expectation, (3) support academic achievement by monitoring academic effort and performance. Unfortunately, many African American children do not have this type of academically responsible authority figure in their lives. With this being the case, we must ensure that all students have access to adults who can provide these supports. Parents, older siblings, educators, and other influential authoritative figures must be equipped with this information. They must also have a willingness to recognize the academic and STEM abilities in their Black students. Perhaps policy makers and social organizations should look to develop K-12 programs with the specific aim of promoting and enhancing the development of academic and STEM identities among African American early adolescents and children via their mothers. Such programs should employ passionate and academically responsible adults who convey to parents (especially mothers) and students that the pursuit of higher education is a foregone conclusion. These programs should be centered in the need for STEM development among African American adolescents, genuine encouragement of academic and STEM abilities, setting high academic standards, and providing academic support. The implementation of such programs could help grow the early seeds of STEM and later increase the number of STEM identified African American students. Nationally, these types of initiatives could generate more interest in STEM disciplines among African American adolescents as many are raised in single parent mother-only households.

This study offers important information about successful African American engineering students, the academic messages received by them, and the people who send these messages. It also identifies those people and messages most influential to the development of the academic and STEM identities of these students. The findings from this study should inform future research in this area, and help to guide future program development. Ultimately, improving our understanding of how to shape successful African American engineering students and contributing to improvements in the educational experiences and outcomes for these students will lead to a stronger, more diverse STEM workforce.

\section{References}

[1] Griffin, B., "Academic Disidentification, Race, and High School Dropouts," The High School Journal Vol. 85, No. 4, 2002, pp. 71-81.

[2] Osborne, J.W., "Academics, Self-Esteem, and Race: A Look at the Underlying Assumptions of the Disidentification Hypothesis," Personality and Social Psychology Bulletin, 1995.

[3] Osborne, J.W., "Race and Academic Disidentification," Journal of Educational Psychology Vol. 89, No. 4, 1997, pp. 728-735.

[4] Sears, K.P., "Extending Disidentification Theory: The Effects of Stereotype Threat on the Self-Concept, Academic Engagement, and School Performance of African American and Latino High School Students," University of Connecticut, 2005, pp. 143.

[5] Steele, C.M., and J. Aronson, "Stereotype Threat and the Intellectual Test Performance of African Americans," Journal of Personality and Social Psychology Vol. 69, No. 5, 1995, pp. 797-811.

[6] Rosenberg, M., Society and the Adolescent Self-Image (Revised Edn.), Middletown, CT: Wesleyan University Press, 1989. 
[7] National Science Foundation, "Women, Minorities, and Persons with Disabilities in Science and Engineering," Arlington, VA, 2007.

[8] National Science Foundation, "Science and Engineering Indicators 2008," 2008.

[9] Census, "United States Census 2000," Washington D.C., 2000.

[10] National Science Foundation, " Realizing America's Potential," The Science and Engineering Workforce, Arlington, VA, 2005.

[11] Prabhu, M.T., "Survey: Women, minorities need STEM encouragement," eSchool News, 2010.

[12] Johnson, C., and W. Kristonis, "The Achievement Gap in Mathematics: A Significant Problem for African American Students," National Forum of Multicultural Issues Journal Vol. 3, No. 1, 2006.

[13] Mubenga, P., "The Struggle of African American Students in the Public Schools," 2006.

[14] Gibson, M.A., "Promoting academic engagement among minority youth: implications from John Ogbu's Shaker Heights ethnography," International Journal of Qualitative Studies in Education Vol. 18, No. 5, 2005, pp. 581-603.

[15] Steele, C.M., "Race and the Schooling of Black Americans," The Atlantic Monthly, 1992, pp. 68-78.

[16] Creswell, J., Qualitative Inquiry and Research Design: Choosing among five approaches, 2nd ed., Thousand Oaks, CA: Sage, 2007.

[17] Moustakas, C., Phenomenological Research Methods: SAGE Publications Ltd., 1994.

[18] Gonzales, N.A., A.M. Cauce, R.J. Friedman, and C.A. Mason, "Family, Peer, and Neighborhood Influences on Academic Achievement Among African-American Adolescents: One-Year Prospective Effects," American Journal of Community Psychology Vol. 24, No. 3, 1996, pp. 365-387.

[19] Israel, G.D., L.J. Beaulieu, and G. Hartless, "The Influence of Family and Community Social Capital on Educational Achievement," Rural Sociology Vol. 66, No. 1, 2001, pp. 43-68.

[20] Salem, D.A., M.A. Zimmerman, and P.C. Notaro, "Effects of Family Structure, Family Proces, and Father Involvement on Psychosocial Outcomes among African American Adolescents," Family Relations Vol. 47, No. 4, 1998, pp. 331-341.

[21] Sharp, S., J. James, K. Kurotsuchi, and J. Waltman, "Insider Information: Social Influence on College Attendance," Proceedings of the Annual Meeting of the American Educational Research Association, New York, NY, April, 19961996.

[22] Bankston III, C.L., and S.J. Caldas, "Family Structure, Schoolmates, and Racial Inequalities in School Achievement," Journal of Marriage and the Family Vol. 60, No. 3, 1998, pp. 715 - 723.

[23] Chubin, D.E., and E. Babco, "'Walking the Talk" in Retention-to-Graduation: Institutional Production of Minority Engineers - A NACME Analysis," 2003.

[24] Jawitz, J., and L. Scott, "Who does not succeed in engineerng at the university of Cape Town? What can one tell from the retention rate?," Fronties in Education Conference, 1997, pp. 71-75.

[25] May, G.S., and D.E. Chubin, "A Retrospective on Undergraduate Engineering Success for Underrepresented Minority Students," Journal of Engineering Education Vol. 92, No. 1, 2003, pp. 27-39.

[26] National Action Council for Minorities in Engineering, "Opening the Pathways to Engineering," White Plains, NY, 2006. 
[27] National Action Council for Minorities in Engineering, "NACME: Engineering Change 2007 Annual Report," 2007.

[28] National Academy of Engineering, "Engineering the Future," Washington, DC: National Academy of Engineering, 2005.

[29] National Science Foundation, "A Companion to Science and Engineering Indicators 2006," America's Pressing Challenge - Building A stronger Foundation, 2006.

[30] National Science Foundation, "National Science Board 2020 Vision for the Natinal Science Foundation," 2006.

[31] National Science Foundation, "Moving Forward to Improve Engineering Education," 2007.

[32] Reichert, M., and M. Absher, "Taking Another Look at Educating African American Engineers: The Importance of Undergraduate Retention," Journal of Engineering Education, 1997.

[33] Seymour, E., and N.M. Hewitt, Issues of Race and Ethnicity. Talking About Leaving, Boulder: Westview Press, 1997.

[34] Maton, K., F. Hrabowski, and C. Schmitt, "African American College Students Excelling in the Sciences: College and Postcollege Outcomes in the Meyerhoff Scholars Program," Journal of Research in Science Teaching Vol. 37, No. 7, 2000, pp. 629-654.

[35] Glesne, C., Becoming Qualitative Researchers, Third ed.: Pearson Education, 2006.

[36] Ezzy, D., Qualitative analysis: Practice and innovation London: Routledge, 2002.

[37] "The use and misuse of self-esteem," Harvard Mental Health Letter, 2007, https://www.health.harvard.edu/newsletters/Harvard _Mental_Health_Letter/2007/June/Rosenberg-Self-Esteem-Scale, accessed on: March 15, 2009.

[38] Sowell, T., "Crippled by Their Culture," Wall Street Journal, 2005, pp. A14. 